\title{
Meeting patients' health information needs in breast cancer center hospitals - a multilevel analysis
}

\author{
Christoph Kowalski ${ }^{1,2^{*}}$, Shoou-Yih D Lee ${ }^{3}$, Lena Ansmann', Simone Wesselmann² and Holger Pfaff ${ }^{1}$
}

\begin{abstract}
Background: Breast cancer patients are confronted with a serious diagnosis that requires them to make important decisions throughout the journey of the disease. For these decisions to be made it is critical that the patients be well informed. Previous studies have been consistent in their findings that breast cancer patients have a high need for information on a wide range of topics. This paper investigates (1) how many patients feel they have unmet information needs after initial surgery, (2) whether the proportion of patients with unmet information needs varies between hospitals where they were treated and (3) whether differences between the hospitals account for some of these variation.
\end{abstract}

Methods: Data from 5,024 newly-diagnosed breast cancer patients treated in 111 breast center hospitals in Germany were analyzed and combined with data on hospital characteristics. Multilevel linear regression models were calculated taking into account hospital characteristics and adjusting for patient case mix.

Results: Younger patients, those receiving mastectomy, having statutory health insurance, not living with a partner and having a foreign native language report higher unmet information needs. The data demonstrate small betweenhospital variation in unmet information needs. In hospitals that provide patient-specific information material and that offer health fairs as well as those that are non-teaching or have lower patient-volume, patients are less likely to report unmet information needs.

Conclusion: We found differences in proportions of patients with unmet information needs between hospitals and that hospitals' structure and process-related attributes of the hospitals were associated with these differences to some extent. Hospitals may contribute to reducing the patients' information needs by means that are not necessarily resource-intensive.

Keywords: Information needs, Breast cancer, Multilevel modelling, Hospital characteristics

\section{Background}

Breast cancer patients are confronted with a serious diagnosis that requires them to make important decisions. These decisions regard treatment and many aspects of everyday life and require patients to be informed of the advantages and disadvantages of different options. According to the Institute of Medicine [1], "many patients have expressed frustration with their inability to participate in

\footnotetext{
* Correspondence: kowalski@krebsgesellschaft.de

'Institute for Medical Sociology, Health Services Research and Rehabilitation Science, Faculty of Human Science and Faculty of Medicine, University of Cologne, Eupener Strasse 129, Cologne 50933, Germany

${ }^{2}$ German Cancer Society, Kuno-Fischer-Straße 8, Berlin 14057, Germany Full list of author information is available at the end of the article
}

decision making, to obtain information they need, to be heard, and to participate in systems of care that are responsive to their needs" (p. 48f). Previous studies have been consistent in their findings that (breast) cancer patients have a high need for information, especially concerning the severity of their condition and their treatment options [2]. Halkett et al. found that breast cancer patients have a consistently high need for information, which does not significantly decrease over the course of treatment [3]. Mistry et al. came to the same conclusion in a heterogeneous sample of cancer patients [4].

Correlates of information needs have been well described in the literature. Matsuyama et al. found a negative 
relationship between education level and the information needs of cancer patients [5]. In a study by Beckjord et al. with a heterogeneous sample of cancer patients, cancer survivors who were younger, had comorbid health conditions and had worse physical or mental health had more information needs [6]. Neumann et al. were able to identify five subgroups of patients with different information needs [7]. According to their classification, nearly one-third of their sample fell into the subgroup with no information needs, nearly $40 \%$ fell into one of the two subgroups with high psychosocial information needs, and approximately one in six fell into each of the remaining two subgroups, one that only had medical information needs and one with both psychosocial and medical information needs. Thus, one persisting problem is the relatively high proportion of breast cancer patients reporting unmet information needs or dissatisfaction with how their information needs are addressed by their health-care providers $[8,9]$. The task of providing the right information to each single patient in a way he or she understands clearly is a challenge for each health-care professional and for the treating hospitals.

One of the most important sources of information for breast cancer patients is the hospital in which he or she is diagnosed and/or treated. Breast care centres in Germany, both certified according to the criteria of the federal state of North Rhine Westphalia [10] and those of the German Cancer Society/German Society of Senology [11], are demanded to undertake huge efforts to provide patients with information, be it paper-based or provided verbally by the hospital staff. Little research, however, has been done to investigate differences of information provision between health-care providers. Hence, research in this field using multilevel approaches has been demanded ([12] p.58). Some studies investigated whether provider characteristics were associated with better informed patients e.g. [13,14], but insight into what promotes or hinders information provision on the hospital level is still sparse. Given the substantial evidence that patient involvement in decision making results in improved outcomes, a hospital-level analysis of what contributes to reducing the proportion of patients with unmet information needs is warranted [15-17].

In this study we investigate which hospital characteristics are associated with patients' unmet information needs. We extend the "conventional set" of structural characteristics employed in most studies, i.e. teaching status, ownership status, and size [18], to include three process approaches that reflect hospitals' efforts to inform and educate patients: providing patient-specific information material, providing access to self-help groups, and organization of health fairs for patients and families [19-21]. Providing tailored information has been described in the literature as a useful strategy of patient education [14] and the IOM has long recommended tailoring of health information to patients' needs [22]. Providing access to selfhelp groups is the second approach investigated. Research evidence on the benefit of self-help group interventions is inconclusive, but a number of studies suggest that selfhelp groups play an important role in establishing patient-centered care [23] and are associated with improved patient outcomes [24]. The third approach investigated is the organization of information fairs for patients and their family. Information fairs contribute to increasing the accessibility of health information, empowering patients to take charge of their own care, and involving families in decision-making and accommodating their needs as caregivers.

We also consider the "conventional set" of hospital characteristics that reflect the hospital structure- i.e., hospital ownership, patient volume, and teaching status. Hospital ownership may be critical because it determines the allocation of financial and nonfinancial resources in hospitals and thus their ability to meet patients' information needs $[25,26]$. Patient volume may influence (unmet) information needs through its impact on clinical workload, coordination, and clinicians' practice experience $[27,28]$. Teaching hospitals have better access to the latest medical knowledge and the most advanced medical technologies, which may enhance their ability to meet patients' information needs than non-teaching hospitals $[29,30]$. On the other hand, teaching hospitals have multiple missions and a more complex organizational structure that may increase the difficulty of coordinating the efforts of clinicians to meet the specific information needs of patients [31]. Also considered in the analysis were patient attributes (e.g., age, education, cancer stage) that may affect (unmet) information needs.

\section{Methods}

We employed a cross-sectional study design. Data were collected from two sources: one was a postal survey of newly diagnosed breast cancer patients treated in German breast cancer center hospitals and the other a postal survey of hospital key informants in those breast cancer center hospitals. The participating hospitals were accredited by the German Cancer Society/German Society for Senology [11]. Both surveys received ethical approval from the Ethics Committee of the Medical Faculty of the University of Cologne, Germany.

\section{Patient survey}

A patient survey was conducted in 2010 in 160 of the 251 certified breast cancer center hospitals. Hospitals participating in the survey were similar to non-participating hospitals in ownership, teaching status, and patient volume. The overall purpose of the survey was to compare the quality of healthcare provided in participating breast 
cancer center hospitals as perceived by patients with a special focus on patient-centeredness and information provision. Details on the survey have been reported elsewhere [8]. Patients undergoing treatment for primary breast cancer in one of the breast cancer center hospitals were invited to self-administer a questionnaire at home after being discharged from the hospital. Patients were included if they: (1) had undergone inpatient surgery between March 22nd and November 31st, 2010, for newlydiagnosed breast cancer, (2) had at least one malignancy, and (3) had at least one postoperative histological evaluation. Before being discharged, eligible patients were asked to give written consent to participate in the survey. Of the 9,354 patients who were eligible, 8,226 consented to the survey and made up the sample of potential respondents. The questionnaire was sent out to those patients within one week of receiving written consent. The survey was designed according to Dillman's Total Design Method, with three contact attempts being made [32]. A total of 7,301 patients responded, with a response rate of $88.8 \%$ of the consenting patients. Survey data were supplemented with clinical data provided by the hospitals.

\section{Hospital key informant survey}

A survey of key informants in breast cancer center hospitals that participated in the patient survey was conducted in 2011 to collect information on hospital structures and activities to strengthen patient-centeredness. The Questionnaire for Breast Cancer Centers Key Informants "FRITZ" [33], along with a letter introducing the study, were sent to one contact in a managerial position within a breast cancer center hospital, i.e., the hospital director/ manager or his/her appointed deputy. The key informant was asked to fill out the questionnaire or to pass it on to another individual who was qualified to respond to the survey because of his/her familiarity with the subject matter. Details on the procedure and results of the survey were reported elsewhere [34]. Of the 160 breast cancer center hospitals that participated in the patient survey, 111 returned the key informant survey (69.4\% response rate). Patient disease characteristics did not vary significantly between hospitals that provided key informant data and those who did not, but hospitals that responded to the key informant survey tended to have better patient survey results [35]. This was especially true for satisfaction with care items, which were not analyzed in the current study. No differences were found between responding and non-responding hospitals in terms of size, ownership, and teaching status.

\section{Measures}

\section{Dependent variable}

Unmet health information needs: The patient survey included nine questions that asked patients whether, during their hospital stay, they would have liked to receive more information on topics of vital interest to them (Table 1). The questions were designed based on expert consensus and have been adopted in surveys of accredited breast cancer centers in Germany since 2005 and reported to hospitals in benchmark reports ever since [36]. The questions were also used in studies on information needs among cancer patients [7]. For each of the survey questions, the response options were "yes", "no", and "don't know". We coded "yes" to 1 and "no" to zero. About $8 \%$ of respondents answered "don't know" to one or more of the items and those answers were treated as missing. A factor analysis revealed a single-factor structure that underlay those nine survey items. Thus, we summed the answers as a composite indicator (value $=0$ to 9 ) to represent unmet information need, with a higher value representing greater unmet information needs. In calculating the composite indicator, we adjusted the score to the 0-9 range for respondents with at least five valid answers. The Cronbach's alpha of the composite indicator was 0.81 , indicating high internal consistency.

\section{Independent variables}

Hospital structural characteristics: Three structural characteristics of hospitals were examined: ownership status (public; charitable; and for-profit), patient volume (annual number of surgeries on breast cancer patients, grouped into: $\leq 100$; 101 to 200; 201 to 300 ; 301 to 400 ; and $>400$ ), and teaching status (yes; no).

Hospital process characteristics: Three approaches of hospitals were investigated that reflect the hospital's effort to inform their patients: provision of patient-specific health information, provision of access to self-help groups, and organization of patient and family health fairs. These approaches were measured, respectively, by the following questions in the hospital key informant survey: "Does the hospital provide health information materials that are tailored to the patient's disease condition? (yes; no)", "Does the hospital make sure that patients have access to selfhelp groups in the hospital? (yes; no)", and "Does the hospital organize information events for patients and families? (yes, on a regular basis for either patients or family or both; no, not on a regular basis)".

Patient attributes: Five socio-demographic variables from the patient survey were included in the analysis: age, education attainment (no education certificate achieved; lower secondary school; intermediate secondary school; technical college/university entrance certificate), living with a partner (yes; no), insurance status (solely statutory health insurance (SHI); SHI plus additional voluntary private insurance/private insurance), and native language (German; other). Before the reunification two different education systems existed in Germany. The categorization was done according to years of schooling and excludes 


\begin{tabular}{|c|c|c|c|}
\hline Would you have liked to receive more information on... & Proportion (hospital min-max) & n & Don't know \\
\hline ... healthy lifestyles (nutrition, alcohol, smoking, etc.)? & $26 \%(4 \%-50 \%)$ & 4,637 & 291 \\
\hline ... physical and mental strains in everyday life? & $39 \%(8 \%-62 \%)$ & 4,586 & 319 \\
\hline ... self-help groups? & $15 \%(0 \%-39 \%)$ & 4,592 & 313 \\
\hline ... books and brochures about your illness? & $13 \%(0 \%-36 \%)$ & 4,671 & 236 \\
\hline ... health-promoting measures? & $42 \%(9 \%-71 \%)$ & 4,643 & 252 \\
\hline ... help and support at home? & $22 \%(0 \%-39 \%)$ & 4,503 & 381 \\
\hline ... psychosocial/psychological support? & $19 \%(3 \%-50 \%)$ & 4,557 & 318 \\
\hline ... rehabilitation possibilities? & $33 \%(6 \%-75 \%)$ & 4,707 & 205 \\
\hline \multirow[t]{2}{*}{... help for daily activities (wigs, household chores)? } & $19 \%(0 \%-39 \%)$ & 4,507 & 381 \\
\hline & Mean (SD) & $n$ & range \\
\hline Unmet information score & $2.32(2.55)$ & 4,809 & $0-9$ \\
\hline
\end{tabular}

tertiary education. The health insurance is a proxy indicator for social status, with higher income groups being more likely to be privately insured or to have SHI with additional voluntary private insurance. In addition to patients' socio-demographic attributes, we also obtained clinical and treatment information on patients from the participating hospitals. The information included cancer stage using UICC categories [37] (Stages 0 to IV), type of surgery (mastectomy; breast conserving treatment) and cancer site (right; left; both).

\section{Statistical analysis}

We performed descriptive and chi-square analyses to examine the prevalence and variation of the three hospital process characteristics that reflect the hospital's effort to adequately inform their patients.

Breast cancer patients were nested within hospitals. To account for this hierarchical structure, we employed hierarchical linear modelling (HLM) to test the association between hospital attributes and patient unmet health information needs [38]. Four sequential models were estimated. First, we ran a fully unconditional model (FUM/ null model) with neither level 1 (patients) nor level 2 (hospitals) predictors to determine the proportion of variance in unmet information needs that was attributable to differences between hospitals. An intraclass correlation coefficient (ICC) was calculated for the FUM to represent the proportion of variance in the dependent variable that was attributable to between-hospital differences. Second, we added patient-level variables (age, cancer stage, cancer site, type of surgery, school leaving certificate, native language, insurance status, and partnership status) to the model. In the third and fourth steps, we added hospitals' structural and process-related characteristics to see if the addition of each group of the variables improved the model fit. HLM 7 software was used for inferential analyses and SPSS 21.0 was used for descriptive and bivariate analyses.
No imputation was performed for missing data. Patient observations with missing information on the dependent variable were excluded. Missing data on the independent variables were included in the model as separate categories to avoid case deletion, and omitted in the results table.

\section{Results}

As seen in Table 1, which presents the average percentages (as well as minimums and maximums) of patients reporting unmet information needs, there remained unmet information needs in German breast cancer center hospitals and the degree of patient unmet information needs varied across hospitals as well as information topics. The four areas with highest unmet information needs were in relation to health promotion activities, physical and mental strains in daily life, rehabilitation services, and healthy lifestyles.

Table 2 presents the descriptive results of the independent patient level variables for those 5,024 patients from hospitals that also participated in the key informant survey. Two thirds of patients were between 50 and 69 years old and less than a quarter had a high school diploma qualifying for university or technical college. Close to $20 \%$ had some form of private insurance. Less than $4 \%$ spoke German as their second language. Roughly three quarters lived with a partner. With regard to disease and treatment characteristics, about one sixth of patients were in an advanced stage of cancer (stage III or IV); approximately $75 \%$ received breast-conserving treatment; the very majority of patients had cancer on one side.

Results showed substantial variation among German breast cancer center hospitals in their efforts to adequately inform their patients (Table 3). Of the approaches, organization of patient and family health fairs was prevalent in 90 hospitals (81.1\%) in the sample. Forty (36.0\%) hospitals provided information material that was tailored to the specific patients. Only three hospitals $(2.8 \%)$ 
Table 2 Patient characteristics $(n=5,024)$

\begin{tabular}{|c|c|}
\hline & Valid percent $(n)$ \\
\hline \multicolumn{2}{|l|}{ Age } \\
\hline $18-39$ & $4.1(204)$ \\
\hline $40-49$ & $17.1(850)$ \\
\hline $50-59$ & $27.7(1,378)$ \\
\hline $60-69$ & $30.1(1,500)$ \\
\hline$\geq 70$ & $21.0(1,044)$ \\
\hline Missing & $(48)$ \\
\hline \multicolumn{2}{|l|}{ Highest education achieved } \\
\hline No education certificate achieved & $2.2(107)$ \\
\hline Lower secondary school (8 or 9 yrs) & $41.4(2,003)$ \\
\hline Intermediate secondary school (10 yrs) & $34.0(1,642)$ \\
\hline High school certificate (12 or 13 yrs) & $22.4(1,081)$ \\
\hline Missing/other & $(191)$ \\
\hline \multicolumn{2}{|l|}{ Health insurance } \\
\hline SHI only & $81.8(4,026)$ \\
\hline Private/SHI + voluntary additional insurance & $18.2(898)$ \\
\hline Missing/other & $(100)$ \\
\hline \multicolumn{2}{|l|}{ Living with a partner } \\
\hline Yes & $73.3(3,644)$ \\
\hline No & $26.7(1,330)$ \\
\hline Missing & $(50)$ \\
\hline \multicolumn{2}{|l|}{ Native language } \\
\hline German & $96.2(4,773)$ \\
\hline Other & $3.8(187)$ \\
\hline Missing & $(64)$ \\
\hline \multicolumn{2}{|l|}{ Stage } \\
\hline Stage 0 & $6.2(264)$ \\
\hline Stage I & $45.6(1,995)$ \\
\hline Stage II & $33.9(1,453)$ \\
\hline Stage III & $10.6(454)$ \\
\hline Stage IV & $3.7(160)$ \\
\hline Missing & (738) \\
\hline \multicolumn{2}{|l|}{ Type of surgery } \\
\hline Mastectomy & $25.4(1,219)$ \\
\hline Breast conserving treatment & $74.6(3,573)$ \\
\hline Missing & $(232)$ \\
\hline \multicolumn{2}{|l|}{ Cancer site } \\
\hline Left & $50.1(2,437)$ \\
\hline Right & $47.2(2,299)$ \\
\hline Both & $2.7(129)$ \\
\hline Missing & $(158)$ \\
\hline
\end{tabular}

provided breast cancer patients no access to self-help groups. No significant associations were found between the structure and process attributes except for providing specific information material that happened more often in teaching than in non-teaching hospitals.

Results of the hierarchical linear model are presented in Table 4. The ICC of the fully unconditional model is 0.030 , suggesting that between-hospital differences accounted for a small amount of variance in patient unmet information needs and that the variation occurred primarily at the patient level. Indeed, most of the patient-level variables examined in the study are statistically significant in explaining patient unmet information needs (model 1). Patients with the following attributes appeared to have greater unmet information needs: undergoing mastectomy, being younger, having statutory insurance coverage (lower income), not living with a partner, and speaking German as a second language. No statistical significance was found for cancer stage, education, and cancer site (not reported in the table for the sake of parsimony).

Addition of hospital structural and process characteristics (models 2 and 3) improved the model fit and led to a reduction of the ICC $(0.025,0.022$, respectively). Based on the change in ICC, those variables contributed to reducing the amount of unexplained variance on the hospital level by over $30 \%$. Two of the three process characteristics - provision of patient-specific health information and organization of patient and family health fairs - had a negative and statistically significant coefficient, suggesting that they contributed to reducing unmet patient information needs. No association was found for providing access to self-help groups.

Among the hospital structural characteristics, teaching status was significantly positively associated with unmet information needs. Higher patient volume appeared to be associated with higher unmet information needs.

\section{Discussion}

Consistent with previous research, substantial proportions of breast cancer patients reported unmet information needs in various areas. In this study we investigated associations of unmet information needs with hospitallevel structure and process characteristics, in addition to patient-level attributes.

In our analysis, most of the variation in patient unmet information needs was accounted for by breast cancer patients' socio-demographic and disease characteristics. These findings are consistent with the literature. Finney Rutten et al. [2], for example, found in their review that age was negatively associated with seeking information among cancer patients. Veloso et al. [39] observed that higher information needs tended to occur in patients with less resources, including social and familial support. A patient characteristic that has not been broadly discussed in the literature and is shown to be strongly associated with unmet information needs in this study is the primary language of the patient. We found breast cancer 
Table 3 Prevalence of hospitals' efforts relating to meeting patient-information needs

\begin{tabular}{|c|c|c|c|c|c|c|c|c|c|}
\hline & \multicolumn{3}{|c|}{ Patient-specific information material } & \multicolumn{3}{|c|}{ Access to self-help groups provided } & \multicolumn{3}{|c|}{ Health fairs for patients/families } \\
\hline & Yes & No & $\mathrm{X}^{2}$ & $\overline{\text { Yes }}$ & No & $\mathrm{X}^{2}$ & Yes & No & $\mathrm{X}^{2}$ \\
\hline All hospitals & $40(36 \%)$ & $71(64 \%)$ & & $105(97 \%)$ & $3(3 \%)$ & & $90(81 \%)$ & $21(19 \%)$ & \\
\hline \multicolumn{10}{|c|}{ Ownership status } \\
\hline Public & $15(27 \%)$ & $41(73 \%)$ & 4.21 & $56(100 \%)$ & $0(0 \%)$ & 4.41 & 49 (88\%) & $7(12 \%)$ & 4.28 \\
\hline Charitable & $13(45 \%)$ & $16(55 \%)$ & & $27(96 \%)$ & $1(4 \%)$ & & $20(69 \%)$ & $9(31 \%)$ & \\
\hline For-profit & $12(46 \%)$ & $14(54 \%)$ & & $22(92 \%)$ & $2(8 \%)$ & & $21(81 \%)$ & $5(19 \%)$ & \\
\hline \multicolumn{10}{|l|}{ Patient volume } \\
\hline$\leq 100$ & $5(38 \%)$ & $8(62 \%)$ & 8.39 & $13(100 \%)$ & $0(0 \%)$ & 2.54 & $10(77 \%)$ & $3(23 \%)$ & 3.46 \\
\hline 101 to 200 & $13(25 \%)$ & $38(75 \%)$ & & 49 (98\%) & $1(2 \%)$ & & 41 (80\%) & $10(20 \%)$ & \\
\hline 201 to 300 & 12 (39\%) & 19 (61\%) & & $28(93 \%)$ & $2(7 \%)$ & & $26(84 \%)$ & $5(16 \%)$ & \\
\hline 301 to 400 & $6(75 \%)$ & $2(25 \%)$ & & $8(100 \%)$ & $0(0 \%)$ & & $5(63 \%)$ & $3(38 \%)$ & \\
\hline$>400$ & $3(50 \%)$ & $3(50 \%)$ & & $6(100 \%)$ & $0(0 \%)$ & & 6 100\%) & $0(0 \%)$ & \\
\hline \multicolumn{10}{|c|}{ Teaching hospital } \\
\hline Yes & $38(40 \%)$ & $57(60 \%)$ & $4.49^{*}$ & 90 (98\%) & $2(2 \%)$ & .84 & $76(80 \%)$ & 19 (20\%) & .50 \\
\hline No & $2(13 \%)$ & 14 (88\%) & & 15 (94\%) & $1(6 \%)$ & & $14(88 \%)$ & $2(13 \%)$ & \\
\hline
\end{tabular}

$\mathrm{N}$; percentages; note: We used pair-wise deletion in the chi-square analysis. Two hospitals had no information on patient volume and three had no information on access to self-help groups. Pearson's chi-square and Fisher's exact test yielded the same results for statistical significance; ${ }^{*}<.05$.

patients that spoke German as a second language were more likely to have unmet information needs. This finding, though not surprising, points to an increasing challenge of health care providers in developed countries in meeting the needs, including health information needs, of immigrant patient populations $[40,41]$.

The ICC of the hierarchical linear modeling was relatively small, suggesting that between-hospital differences (i.e., hospital-level factors) contributed to explaining the variance in patient unmet information needs only to a little extent. In Germany, breast cancer centers were established with the aim to reach a consistently high level of care quality. This may explain the small ICC in the analysis. In fact, the ICC in our analysis was comparable with those reported in previous research and analyses that show a high ICC in relatively standardized health care settings are rare. Sjetne et al., for example, reported ICCs ranging from 0.002-0.065 for several patient experience indicators [31].

We, however, found that breast cancer patients treated in teaching hospitals were significantly more likely to report unmet information needs. The research literature has reported inconsistent results regarding the performance of teaching hospitals perform in different areas. Several studies found that, in comparison to non-teaching hospitals, teaching/academic hospitals achieved better results in process and, especially, outcome aspects of clinical care quality [42-45]. Landon et al. found teaching status to be associated with better diagnosis and treatment performance, but worse patient counselling [46]. An explanation of these various results is that teaching hospitals have multiple missions and that they have difficulties simultaneously maintaining excellence in clinical care, teaching and research, and successfully meeting patients' information needs.

We in addition found that two of the approaches that reflect the hospitals's effort to inform and educate their patients - provision of patient-specific health information material and organization of patient and family health fairs - were associated with smaller unmet information needs. Epstein \& Street [12] and the IOM [1] called for research to examine the organizational context of patient-centered care. Mulcare et al. pointed out that few studies had investigated factors explaining patient information needs [47]. Our study fills these gaps to some extent, but must be interpreted with caution: Neither do we know what specifically was done during health-fairs nor do we know what quality the information material was. In addition, we need to rely on information provided by the key informants' and cannot exclude over-reporting.

Our findings, however, may have relevant practical implications. Considering the large amount of information a patient might receive during her hospital stay, provision of tailored information that is most relevant to the patients and that meets her specific needs is critical. While tailoring the content of health information to patients is important, it may be equally important to consider the appropriate way that information is delivered to patients in written form, using graphic display or multi-media presentation, or through oral communication $[48,49]$. It is reassuring to note that hospitals' investment in health fairs may be worthwhile. Compared to other hospital-level health activities and interventions such as case management, health fairs are relatively "resource-light". There is so 
Table 4 Results of the hierarchical linear regression models on unmet information needs

\begin{tabular}{|c|c|c|c|}
\hline & Model 1 & Model 2 & Model 3 \\
\hline Intercept & $1.82^{* * *}$ & $1.53^{* * *}$ & $1.68^{* * *}$ \\
\hline \multicolumn{4}{|l|}{ Patient characteristics } \\
\hline Mastectomy & $.23^{*}$ & $.23^{*}$ & $.23^{* *}$ \\
\hline Statutory health insurance & $.18^{*}$ & $.18^{*}$ & $.19^{*}$ \\
\hline Not living with a partner & $.37^{* * *}$ & $.36^{* * *}$ & $.37^{* * *}$ \\
\hline \multicolumn{4}{|l|}{ Age groups (ref. 60 to 69) } \\
\hline$\leq 39$ & $.64^{* * *}$ & $.63^{* * *}$ & $.62^{* * *}$ \\
\hline 40 to 49 & $.40^{* *}$ & $.41^{* *}$ & $.40^{* *}$ \\
\hline 50 to 59 & $.42^{* *}$ & $.43^{* * *}$ & $.43^{* * *}$ \\
\hline$\geq 70$ & $-.47^{* * *}$ & $-.47^{* * *}$ & $-.47^{* * *}$ \\
\hline Native language other than German & $.82^{* * *}$ & $.82^{* * *}$ & $.81^{* * *}$ \\
\hline \multicolumn{4}{|l|}{ Hospital characteristics - structure } \\
\hline Teaching & & .23 & $.32^{* *}$ \\
\hline \multicolumn{4}{|l|}{ Patient volume (ref. 101 to 200) } \\
\hline$\leq 100$ & & -.09 & -.05 \\
\hline 201 to 300 & & $.41^{* *}$ & $.45^{* *}$ \\
\hline 301 to 400 & & -.07 & .09 \\
\hline$\geq 401$ & & .04 & .21 \\
\hline \multicolumn{4}{|l|}{ Ownership (ref. for-profit) } \\
\hline Public & & -.01 & -.11 \\
\hline Charitable & & -.11 & -.18 \\
\hline \multicolumn{4}{|l|}{ Hospital characteristics - process } \\
\hline Patient-specific information material & & & $-.39 * *$ \\
\hline Access to self-help groups & & & .18 \\
\hline Health fairs for patients/family & & & $-.26^{*}$ \\
\hline \multicolumn{4}{|l|}{ Variance components for random effects: } \\
\hline Between-hospital variance $\left(\tau_{00}\right)$; SD & $.20 ; .44^{* * *}$ & $.16 ; .40^{* * *}$ & $.14 ; .37^{* * *}$ \\
\hline Degrees of freedom & 110 & 98 & 98 \\
\hline Chi-square & 262.91 & 212.21 & 185.16 \\
\hline ICC (FUM: .030) & .032 & .025 & .022 \\
\hline
\end{tabular}

Models adjusted for additional patient characteristics (stage, cancer site, education); $\mathrm{n}=4,809$ patients; $\mathrm{N}=111$ hospitals; ${ }^{*} \mathrm{p}<.05 ;{ }^{* *} \mathrm{p}<.01 ;{ }^{* * *} \mathrm{p}<.001$.

far little evidence in the literature on the effectiveness of health fairs and specific aspects that make health fairs successful. Neither is there a consensus on the utility of different types of information and educational events for patients, friends, and family. The results reported here need further investigation with respect to both tailoring patient information and organizing health fairs.

We failed to find a significant association between provision of access to self-help groups and patient information needs. There are three likely explanations. First, the approach was implemented in the majority of studied breast cancer center hospitals. Thus, the variation may be too small to detect any significant association.
Second, access to self-help groups, unlike the other two "direct contact" approaches [50] to meeting patient information needs, may not be as an effective way to facilitate and manage the flow of useful health information to patients. Third, it could be that self-help groups are more effective in providing emotional and tangible support rather than disseminating health information.

Several research limitations should be considered when interpreting the results of this study. The cross-sectional design of the study made causal interpretations difficult. Furthermore, the results were obtained from a sample of breast cancer patients treated in accredited breast cancer center hospitals in Germany. It is unclear whether the results are generalizable to other patient populations and other health care settings in a different country. We were unable to assess systematic differences in patient participation in the survey. Patients with a low health literacy level and less capable of making informed health care decisions may be less likely to respond to the survey and may have greater unmet information needs. To the extent this is true, we may have under-estimated the degrees of unmet information needs. The same problem of underestimation may occur in patients with more severe breast cancer conditions.

\section{Conclusions}

A fundamental aspect of patient-centered care is patient education and meeting the information needs of patients. It is only when patients are informed that they can become an active partner in the process of their care. We found differences in proportions of patients with unmet information needs between hospitals and that hospitals' structure and process-related attributes of the hospitals were associated with these differences to some extent. The two attributes that are most easily to change are relatively "low-tech". Thus, a lesson in our study is that hospitals may contribute to reducing the patients' information needs by means that are not necessarily resourceintensive. The challenge may be in the shifting of philosophy, attitude, and priority on the part of health care providers.

\section{Competing interests}

The authors declare that they have no competing interests.

\section{Authors' contributions}

CK and SYDL planned data analysis and drafted the manuscript. CK and LA analysed the data. CK, SW and HP developed the study framework and the patient survey. All authors read, critically reviewed, and approved the final manuscript.

\section{Acknowledgements}

We would like to thank the patients who participated in the survey and the breast cancer centres supporting this study. We confirm that all patient identifiers have been removed or disguised so that the patients described are not identifiable. Thanks to Markus Alich, care research lab manager at the IMVR, who assisted in patient data collection, and to Stefanie Sauter, who contributed to the key informant interviews. The patient survey was initiated 
and supported by the German Cancer Society, with partial funding from AVON. The cost for the key informant interviews was covered by capital resources of the IMVR. The hospitals provided patients' addresses and clinical information, as reported. The hospitals were not involved in the analysis and interpretation of results, or preparation of this manuscript. The writing was done during the first author's stay at the University of Michigan that was financed by the German Research Foundation (Grant number: Ko 3856/2).

\section{Author details}

${ }^{1}$ Institute for Medical Sociology, Health Services Research and Rehabilitation Science, Faculty of Human Science and Faculty of Medicine, University of Cologne, Eupener Strasse 129, Cologne 50933, Germany. ${ }^{2}$ German Cancer Society, Kuno-Fischer-Straße 8, Berlin 14057, Germany. ${ }^{3}$ Department of Health Management and Policy, The University of Michigan School of Public Health, 1420 Washington Heights, Ann Arbor 48109-2029, MI, USA.

Received: 1 June 2014 Accepted: 12 November 2014

Published online: 25 November 2014

\section{References}

1. Institute of Medicine: Crossing the quality chasm. Washington D.C., USA: National Academy Press; 2001.

2. Finney Rutten $\amalg$, Arora NK, Bakos AD, Aziz N, Rowland J: Information needs and sources of information among cancer patients: a systematic review of research (1980-2003). Patient Educ Couns 2005, 57:250-261.

3. Halkett GK, Kristjanson LJ, Lobb E, Little J, Shaw T, Taylor M, Spry N: Information needs and preferences of women as they proceed through radiotherapy for breast cancer. Patient Educ Couns 2011, 86:396-404.

4. Mistry A, Wilson S, Priestman T, Damery S, Haque M: How do the information needs of cancer patients differ at different stages of the cancer journey? A cross-sectional survey. JRSM Short Rep 2010, 1:30.

5. Matsuyama RK, Wilson-Genderson M, Kuhn L, Moghanaki D, Vachhani H, Paasche-Orlow M: Education level, not health literacy, associated with information needs for patients with cancer. Patient Educ Couns 2011, 85:e229-e236.

6. Beckjord EB, Arora NK, McLaughlin W, Oakley-Girvan I, Hamilton AS, Hesse BW: Health-related information needs in a large and diverse sample of adult cancer survivors: implications for cancer care. J Cancer Surviv 2008, 2:179-189.

7. Neumann M, Wirtz M, Ernstmann N, Ommen O, Langler A, Edelhauser F, Scheffer C, Tauschel D, Pfaff H: Identifying and predicting subgroups of information needs among cancer patients: an initial study using latent class analysis. Support Care Cancer 2011, 19:1197-1209.

8. Kowalski C, Wesselmann S, Kreienberg R, Schulte H, Pfaff H: The patients' view on accredited breast cancer centers: strengths and potential for improvement. Geburtsh Frauenheilk 2012, 72:137-143.

9. Arora NK, Johnson P, Gustafson DH, McTavish F, Hawkins RP, Pingree S: Barriers to information access, perceived health competence, and psychosocial health outcomes: test of a mediation model in a breast cancer sample. Patient Educ Couns 2002, 47:37-46.

10. ÄKZERT: Verfahren zur Zertifizierung von Brustzentren in NRW, Version 2012. 2012, http://www.mgepa.nrw.de/mediapool/pdf/gesundheit/ Anforderungskatalog_Brustzentren_NRW_2014.pdf, retrieved 30 October 2012, 2011.

11. Deutsche Krebsgesellschaft, Deutsche Gesellschaft für Senologie: Fachliche Anforderungen für die Zertifizierung von Brustzentren durch die Deutsche Krebsgesellschaft und die Deutsche Gesellschaft für Senologie. 2003, [http://www.krebsgesellschaft.de/gcs/german-cancer-society/certification. html?file=files/dkg/deutsche-krebsgesellschaft/content/pdf/Zertifizierung/ engl\%20eb_OZ-D2\%20_120328_Engl.pdf], retrieved 23 August 2013

12. Epstein RM, Street RL: Patient-centered communication in cancer care. Promoting healing and reducing suffering. NIH Publication No. 07-6225. National Cancer Institute: Bethesda, USA; 2007.

13. Butow PN, Maclean M, Dunn SM, Tattersall MH, Boyer MJ: The dynamics of change: cancer patients' preferences for information, involvement and support. Ann Oncol 1997, 8:857-863.

14. Douma KF, Koning CC, de Haes HC, Zandbelt LC, Stalpers L, Smets EM: Do radiation oncologists tailor information to patients' needs? And, if so, does it affect patients? Acta Oncol 2012, 51:512-520.

15. Heisler M, Bouknight RR, Hayward RA, Smith DM, Kerr EA: The relative importance of physician communication, participatory decision making, and patient understanding in diabetes self-management. J Gen Intern Med 2002, 17:243-252.

16. Arora NK: Interacting with cancer patients: the significance of physicians' communication behavior. Soc Sci Med 2003, 57:791-806.

17. Edwards A, Elwyn G, Hood K, Atwell C, Robling M, Houston H, Kinnersley P, Russell I: Patient-based outcome results from a cluster randomized trial of shared decision making skill development and use of risk communication aids in general practice. Fam Pract 2004, 21:347-354.

18. Hearld LR, Alexander JA, Fraser I, Jiang HJ: How do hospital organizational structure and processes affect quality of care? A critical review of research methods. Med Care Res Rev 2008, 65:259-299.

19. Kreuter MW, Strecher VJ, Glassman B: One size does not fit all: the case for tailoring print materials. Ann Behav Med 1999, 21:276-283.

20. Kowalski C, Weber R, Jung J, Ansmann L, Pfaff H: In-house information about and contact with self-help groups in breast cancer patients: associated with patient and hospital characteristics? Eur J Cancer Care 2012, 21:205-212

21. Dillon DL, Sternas K: Designing a successful health fair to promote individual, family, and community health. J Community Health Nurs 1997, 14:1-14.

22. Hewitt M, Greenfield S, Stovall E: From cancer patient to cancer survivor: lost in transition. Washington, DC, USA: National Academies Press; 2006.

23. Nickel S, Trojan A, Kofahl C: Increasing patient centredness in outpatient care through closer collaboration with patient groups?: an exploratory study on the views of health care professionals working in quality management for office-based physicians in Germany. Health Policy 2012, 107:249-257.

24. Hoey LM, leropoli SC, White VM, Jefford M: Systematic review of peer-support programs for people with cancer. Patient Educ Couns 2008, 70:315-337.

25. Sloan FA: Not-for-profit ownership and hospital behavior. In Handbook of Health Economics, Volume 1. Edited by Pauly MV, Mcguire TG, Barros PP. Philadelphia, PA: Elsevier; 2000:1141-1174. Part B.

26. Teno JM, Susan L, Mitchell SL, Gozalo PL, Dosa D, Hsu A, Intrator O, Mor V: Hospital characteristics associated with feeding tube placement in nursing home residents with advanced cognitive impairment. JAMA 2010, 303:544-550.

27. Birkmeyer JD, Stukel TA, Siewers AE, Goodney PP, Wennberg DE, Lucas FL: Surgeon volume and operative mortality in the United States. N Engl J Med 2003, 349:2117-2127.

28. Livingston $\mathrm{EH}, \mathrm{CaO} \mathrm{J}$ : Procedure volume as a predictor of surgical outcomes. JAMA 2010, 304:95-97.

29. Cox JL, Chen E, Naylor CD: Revascularization after acute myocardial infarction: impact of hospital teaching status and on-site invasive facilities. J Gen Intern Med 1994, 9:674-678.

30. Keeler EB, Rubenstein LV, Kahn KL, Draper D, Harrison ER, McGinty MJ, Rogers WH, Brook RH: Hospital characteristics and quality of care. JAMA 1992, 268:1709-1714.

31. Sjetne IS, Veenstra M, Stavem K: The effect of hospital size and teaching status on patient experiences with hospital care: A multilevel analysis. Med Care 2007, 45:252-258.

32. Dillman DA: Mail and telephone survey: The total design method. New York, USA: Wiley \& Sons; 1978.

33. Pfaff $H$, Ansmann $L$, Kowalski C: Befragung von Schlüsselpersonen in von der Deutschen Krebsgesellschaft zertifizierten Brustkrebszentren 2011. Ergebnisbericht. Köln. Germany: IMVR Research Reports; 2011.

34. Kowalski C, Wesselmann S, Ansmann L, Kreienberg R, Pfaff H: Key informants' perspectives on accredited breast cancer centres: results of a survey. Geburtsh Frauenheilk 2012, 72:235-242.

35. Kowalski C, Ansmann L, Wesselmann S, Pfaff H: Zertifizierte Brustkrebszentren aus Sicht von Patientinnen und Zentrumsleitungen. DKG Forum 2012, 27:405-409.

36. Kowalski C, Würstlein R, Steffen P, Harbeck N, Pfaff H: Vier Jahre Patientinnenbefragung im Rahmen der (Re-)Zertifizierung der Brustzentren in Nordrhein-Westfalen. Geburtsh Frauenheilk 2011, 71:67-72.

37. Sobin LH, Wittekind C: UICC TNM Classification of malignant tumors. 6th edition. New York, USA: John Wiley \& Sons; 2002

38. Raudenbush SW, Bryk AS: Hierarchical linear models. Applications and data analysis methods. $2^{\text {nd }}$ edition. Thousand Oaks, CA: Sage; 2002.

39. Veloso AG, Sperling C, Vilstrup Holm L, Nicolaisen A, Rottmann N, Thayssen S, Depont Christensen R, Lehmann Knudsen J, Hansen DG: Unmet needs in cancer rehabilitation during the early cancer trajectory - a nationwide patient survey. Acta Oncol 2013, 52:372-381. 
40. Lapane KL, Goldman RE, Quilliam BJ, Hume AL, Eaton CB: Tailored DVDs: a novel strategy for educating racially and ethnically diverse older adults about their medicines. Int J Med Inform 2012, 81:852-860.

41. Kreps GL, Sparks L: Meeting the health literacy needs of immigrant populations. Patient Educ Couns 2008, 71:328-332.

42. Allison JJ, Kiefe Cl, Weissmann NW, Person SD, Rouse A, Canton J, Baecker D, Williams OD, Farmer R, Centor RM: Relationship of hospital teaching status with quality of care and mortality for medicare patients with acute MI. JAMA 2000, 284:1256-1262.

43. Ayanian JZ, Weissman JS: Teaching hospitals and quality of care: a review of the literature. Milbank Q 2002, 80:569-593.

44. Grilli R, Minozzi S, Tinazzi A, Labianca R, Sheldon TA, Liberati A: Do specialists do it better? The impact of specialization on the processes and outcomes of care for cancer patients. Ann Oncol 1998, 9:365-374.

45. Kupersmith J: Quality of care in teaching hospitals: a literature review. Acad Med 2005, 80:458-466.

46. Landon BE, Normand SL, Lessler A, O'Malley AJ, Schmaltz S, Loeb JM, McNeil BJ: Quality of care for the treatment of acute medical conditions in US hospitals. Archi Intern Med 2006, 166:2511-2517.

47. Mulcare H, Schofield P, Kashima Y, Milgrom J, Wirth A, Bishop M, Wheeler G: Adjustment to cancer and the information needs of people with lung cancer. Psychooncology 2011, 20:488-496.

48. Kiesler DJ, Auerbach SM: Optimal matches of patient preferences for information, decision-making and interpersonal behavior: Evidence, models and interventions. Patient Educ Couns 2006, 61:319-341.

49. Wynia MK: Making it easier to do the right thing: a modern communication Ql agenda. Patient Educ Couns 2012, 88:364-366.

50. Rathert C, Wyrwich MD, Boren SA: Patient-centered care and outcomes: A systematic review of the literature. Med Care Res Rev 2013, 70:351-379.

doi:10.1186/s12913-014-0601-6

Cite this article as: Kowalski et al:: Meeting patients' health information needs in breast cancer center hospitals - a multilevel analysis. BMC Health Services Research 2014 14:601.

\section{Submit your next manuscript to BioMed Central and take full advantage of:}

- Convenient online submission

- Thorough peer review

- No space constraints or color figure charges

- Immediate publication on acceptance

- Inclusion in PubMed, CAS, Scopus and Google Scholar

- Research which is freely available for redistribution 